\title{
WHAT LIES BENEATH: DIGGING INTO THE SOIL MICROBIOME
}

SOIL IS FULL OF A STAGGERINGLY LARGE NUMBER AND DIVERSITY OF MICROBES. THIS MICROBIAL COMMUNITY, OR MICROBIOME, CAN HELP OR HINDER THE GROWTH OF PLANTS. RESEARCHERS FROM THE UNIVERSITY OF MANCHESTER IN THE UK AND THE UNIVERSITY OF MINNESOTA IN THE US HAVE TEAMED UP TO UNDERSTAND HOW THE MICROBES FOUND IN SOIL INTERACT WITH ONE ANOTHER AND WITH PLANTS, AND WHETHER THIS KNOWLEDGE COULD BE HARNESSED TO BRING BENEFITS TO AGRICULTURE

\section{TALK LIKE A MICROBIOLOGIST}

DRY LAB - a scientific laboratory involving principally computational work

SIGNAL - a biological, chemical or physical event that leads to a change in an organism's behaviour

\section{EMBEDDED GENETIC RECORDER}

(EGR) - an engineered DNA sequence that can 'record' the response to an unknown signal

GENOME - the complete set of genes of an organism

MICROBE - a microorganism, such as a bacterium

The soil microbiome can have a profound effect on the productivity of crops, which leads to challenges for agriculture. While microbial pathogens can sometimes decimate entire fields, other microbes can help boost growth and productivity. To make things more complicated, microbes exchange signals with each other that change their functions in complex ways. Five teams of researchers, two from the University of Manchester in the UK and three from the University of Minnesota in the US, have joined forces to understand the complex interactions going on beneath the soil's surface.

\section{MICROBIAL MURMURINGS}

"To feed the world's population, we need healthy
MICROBIOME - all the microorganisms of a particular environment

PATHOGEN - a microbe that causes disease

PLASMID - a small DNA molecule carrying genetic information that is easily exchanged between organisms. Often used for genetic modification

WET LAB - a scientific laboratory involving practical experiments
However, given the many different interactions taking place, gaining this understanding is no simple undertaking. "Microbiomes can profoundly affect plant growth and health, such as through suppressing disease or enhancing drought tolerance," says Jack Connolly from the University of Manchester. "Signalling within the soil plays a key role in influencing these impacts." Tapping into this signalling process could therefore yield key insights. "If we know how bacteria talk to each other, we can interfere with that cross-talk in ways that bring benefits for crops," says Jeremy. "We can also 'eavesdrop' to get advance warning of whether pathogens will become a problem."

\section{LISTENING IN}

The researchers are cracking this communication code using a range of clever tools in their arsenal, each yielding unique insights. "Bacteria talk to one another using signal molecules," says Kamila Schmidt from the University of Manchester. "We can analyse these interactions using 'omics' approaches genomics, transcriptomics or metabolomics." These techniques tell researchers if the bacteria can make signals, are trying to make signals, or if signals were made. For instance, metabolomics involves extracting and analysing the signal molecules being released.

Another technique involves some nifty genetic engineering. "We insert an engineered DNA sequence, which we have named an Embedded Genetic Recorder (EGR), into the genome of the target soil microbe," says Maxime Boneza 
from the University of Minnesota. "The EGR is designed to be activated when a particular signal is received, and what makes the EGR unique is that this activation can be detected in the soil allowing us to 'listen in' on signalling events where and when they occur."

\section{A TALE OF TWO UNIVERSITIES}

While the two universities are working closely together, they each have their own areas of focus. The Minnesota team is developing the EGRs, while the Manchester team is looking into how to get genetic material (such as EGRs) into the genome of a particular bacterium called Streptomyces. "These bacteria are prolific antibiotic producers, and widespread members of soil microbial communities, but are often particularly challenging to genetically engineer," says Jack. "We are engineering new plasmids to allow us to manipulate the genomes of these strains."

Once these tests have gone through, the two teams will combine their work. "EGRs developed in Minnesota will be delivered into hundreds of locations within the Streptomyces genome using the genetic methods optimised by the Manchester team," says Jack. "This will allow us to record the complex response to a diverse mixture of soil signals impacting on our recorder strains at once."

\section{COMBINING SKILL SETS}

"This project is bringing together a diverse range of disciplines, including biology, chemistry, mathematics and computational biology," says Stephen Heinsch from the University of Minnesota. "While the project is rooted in microbial ecology and plant pathology, we are making use of the latest advances in synthetic biology, high-throughput chemistry and computational analyses."

This diversity is brought to life by the different skill sets of the researchers. While those in the 'wet labs' are directly investigating and modifying these microbial communities, the researchers in the 'dry labs' are taking a different, complementary, approach. "We will make computer models that represent how microbial species grow when they have different resources available," says Jeremy. "These models will help us predict how different species will compete or cooperate, and so help us theorise how to modify microbiomes in useful ways." As well as modelling, the computer labs will also be essential for data processing. "Our methods produce huge datasets with immense complexity," says Stephen. "Techniques such as machine learning will help us find patterns within this complexity."

\section{SOCIETAL IMPACT}

The team hopes that ultimately their research will help agriculture develop sophisticated and eco-friendly approaches to boosting yields. "This knowledge could unlock tangible benefits to crops, using an optimised soil microbiome to fight pathogens and promote growth," says Jack.

Though agriculture will be a primary beneficiary, Stephen believes this work could herald the beginning of a new era for other sectors too. "In the near future, we may be able to design beneficial microbial communities for the human gut, or to clean up environmental pollutants," he says. "In the far future, my dream is to see engineered microbial communities being used to terraform other planets!"

\section{MEET THE TEAM}

\author{
DR JACK CONNOLLY \\ NATURAL PRODUCT \\ BIOCHEMISTRY \\ THE UNIVERSITY OF \\ I work in the wet lab and am developing technologies \\ to edit the genomes of key soil bacteria. We will use \\ these methods to insert Minnesota's EGRs into the \\ Streptomyces genome.
} MANCHESTER, UK

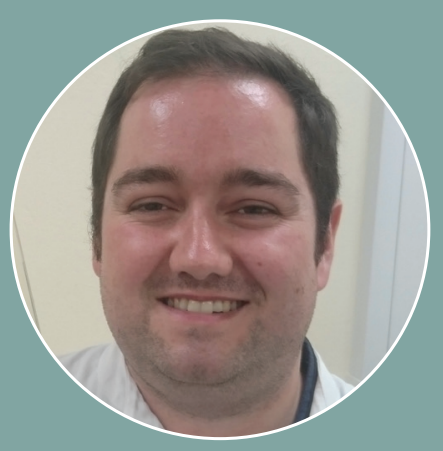

I have a background in microbiology, including working with Streptomyces. I was drawn to this project because the lab is run by highly regarded experts, and I felt it would be a great place to progress to independence myself. I find our multifaceted project intriguing, and there is lots left to understand.

I am motivated by the need to understand each system in a certain way, or the effects of changing a DNA sequence. I enjoy the investigative process of the lab and the subsequent analysis and thinking.

As a youngster, I was naturally drawn towards we investigate - such as why mutated bacteria behave mathematics and physics, and after school I worked in statistics. It was during this time that I became intrigued by molecular biology, in particular the beauty of the core rules behind how cells function.

I am analytical, logical and methodical in my lab work. I enjoy the collaborative nature of our work and have the perseverance needed to overcome the challenges that come up.

At school, biology and chemistry would be important, but otherwise I recommend letting your natural interests guide you. At university, consider courses such as biological sciences, biochemistry or chemistry.

Follow what you find interesting and exciting at each academic stage. While I was an undergraduate, I would never have guessed I would end up specialising in natural product biochemistry. 
DR KAMILA SCHMIDT BIOCHEMISTRY THE UNIVERSITY OF MANCHESTER, UK

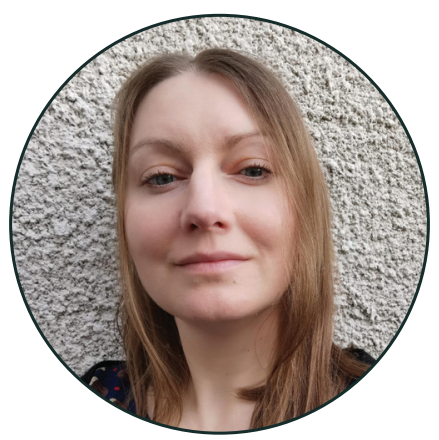

I provide technical support for experiments that quantify microbial signal molecules. I do a mixture of experimental and computational work.

I completed a PhD in biochemistry with a project in metabolomics, and then worked as a research technician in a synthetic biology project. My current role builds on my previous experience.

I am curious about the outcomes of our experiments and projects and enjoy seeing how the knowledge gained can be applied to the wider world.

At school I was interested in science and music. My mum was a biology teacher and got me interested in science. I was also inspired by the TV show Star Trek, which demonstrates through fiction how science can play a pivotal role in discovery.

I enjoy learning new techniques, new scientific methods, and new software that all advance our scientific knowledge. I also enjoy working with students and scientists from all around the world.

The sciences are all useful at school. At university, specialising in chemistry, biochemistry or biotechnology are all sensible routes.

Never give up. If you really want something, work hard and you'll get there.
WENDY HUGHES

PLANT PATHOLOGY

THE UNIVERSITY OF

MINNESOTA, USA

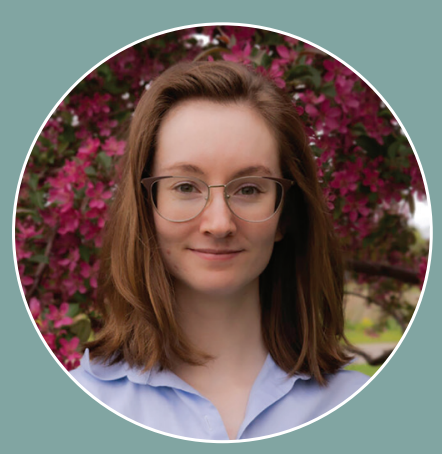

For this research, I will perform experiments looking at how EGRs can be used on a broader ecological platform, once the EGRs have been developed by the other teams.

I joined this research project when one of the lab heads and I discussed my interest in microbial communication, and she offered for me to participate in the meetings.

I am motivated by the mystery surrounding microbial communication. The idea of microbes talking to one another using chemicals fascinates me!

I was always interested in science as a child. This interest solidified when I found a connection between my high school chemistry class and biology class and realised that all science is connected.

Becoming comfortable with failure has really helped me. In science, more experiments fail than succeed handling it well and learning from it is how you enjoy working in the field.

Microbiology needs a core understanding of lots of subjects. I blew off organic chemistry but now find myself relearning it. A broad biological and chemical understanding will help you out.

Don't be afraid to ask for help when you need it, whether in class, work, or your personal life.
MAXIME BONEZA MICROBIAL ENGINEER THE UNIVERSITY OF MINNESOTA, USA

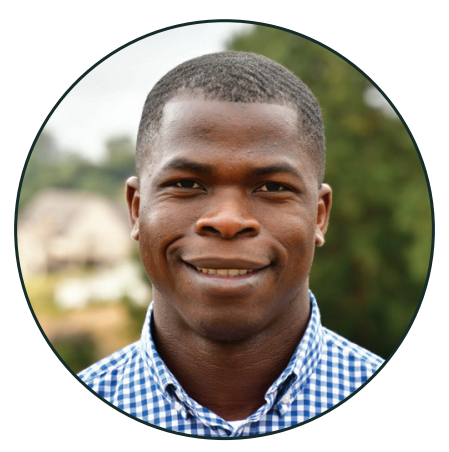

I am a PhD student working to genetically engineer plasmids so that they deliver the EGR into Streptomyces.

I have a Bachelor of Science in chemistry, and before joining this project spent two years working for an industrial chemical manufacturing company. When I began my PhD thesis, I immediately felt connected to this project, due to the way it related to agriculture and the aspect of natural product discovery. I had no experience working with microorganisms so there was a steep learning curve involved.

Knowing that this research could have a positive impact on agriculture provides me with motivation. Our findings could revolutionise the way that farmers protect plants from pathogens.
Growing up, I was interested in herbal medicine, until I moved to Houston. Then I wanted to be an astronaut, but this changed again once I was in college, working with an advisor to understand the antioxidants found in herbal plants. I believe this is where my interest as a researcher began in earnest.

I am resilient and pour everything I have into a task. I also take feedback seriously and use this to help my growth.

Recommending what you should study is tricky because it depends on your own interests and curiosities. I personally did a lot of chemistry courses at college, which I certainly don't regret.

Always have the curiosity to learn new things. Respond to feedback but do not let it slow yo down. 


\section{STEPHEN HEINSCH}

COMPUTATIONAL

BIOLOGY

THE UNIVERSITY OF

MINNESOTA, USA

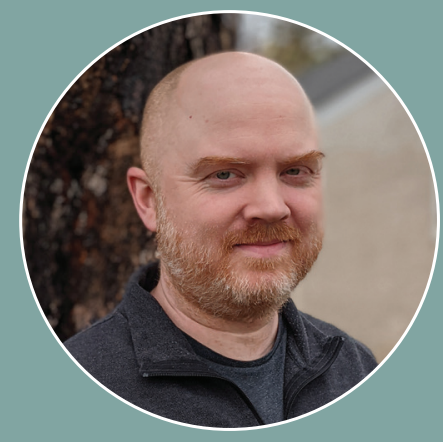

I am in a hybrid role between the wet lab and dry lab. In the wet lab, I have contributed to the development of the EGR and sequencing microbial genomes, while in the dry lab I lead an engineered microbiome gene-expression study to learn about unique genetic responses to chemical signalling.

I have a background in both molecular biology and computer science, and began working on the engineered microbiome gene-expression study when I started my PhD. Later, my work came to fit in nicely with the project involving soil signalling.

I am intrigued by big, complex problems, and am drawn to develop solutions to them. The thought of deploying technology I helped develop into the world excites me.

As a child, I was deeply interested in language and computers, and spent time studying Japanese and video game programming. It wasn't until college I became interested in biology. One of my professors shared an analogy of cells as factories and proteins as custom-built machines and, given my background in programming, this piqued my interest in synthetic biology.

Being willing to accept when my assumptions are incorrect, and not being discouraged by failure, have both helped me enormously in my career.

Start programming as soon as you can. There are so many free resources online that you can use to teach yourself. Subjects such as biology and chemistry are also important at school. For me, my most useful college classes were cell biology, genetics, biochemistry and organic chemistry. I also recommend taking mathematics classes, especially in statistics, calculus and linear algebra.

Get involved in research in your field as early as possible. Solving problems in the lab is a great learning experience.

\section{DR JEREMY CHACÓN} MICROBIAL ECOLOGY THE UNIVERSITY OF MINNESOTA, USA

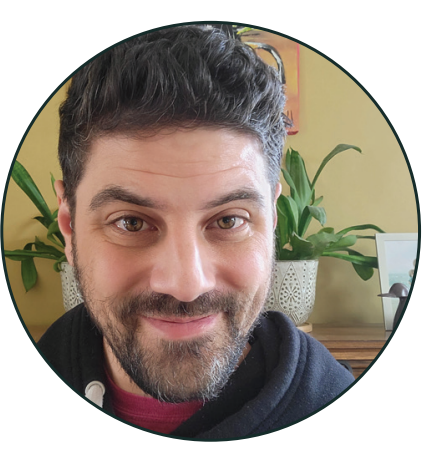

I make computer model representations of the Streptomyces bacteria we study. I input the functions of all the genes that code for metabolic enzymes and then see how the bacteria grow in various simulated environments.

I have worked a lot with computer models in the past but wanted to be a part of something with a more applied outcome, so when this opportunity arose, I jumped for it.

I enjoy solving problems, being creative and being surprised. Science provides an outlet for all these things.

I've always loved ecology, even though I didn't know it was called that until college. I was the kid who'd be watching insects when I was supposed to be playing sports. I am also an avid fiction reader and amateur musician.
I pressure myself to finish things. There are very few external deadlines in science, so you have to impose this structure yourself. Additionally, I don't mind being wrong or not understanding - as scientists we are always trying to understand new things, which involves a lot of being wrong along the way.

In addition to science courses, I recommend working on your writing and mathematical ability. I also believe it's important to keep your creative side going, so an arts subject is useful.

The skills you need within a lab can be very different to those needed in the classroom. I strongly recommend finding a way to spend some time in a lab. This will help you learn what lab work is like, and also begin to develop a network or even find a mentor.

\section{(2)}

This material is based upon work supported by the U.S. National Science Foundation under grant IOS-935458 (University of Minnesota), and UK Research and Innovation (UKRI) grant (NE/T010959/1) from the Natural Environment Research Council (NERC) (University of Manchester). Any opinions, findings, and conclusions or recommendations expressed in this material are those of the author(s) and do not necessarily reflect the views of the U.S. National Science Foundation.

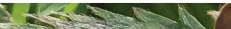

